\title{
Factors that Precipitate and Mitigate Crises in Ministry
}

Barry Fallon, ${ }^{1}$ Simon Rice, ${ }^{2}$ Joan Wright Howie $^{3}$

Abstract Using a modified Delphi technique, this study reports mixed-method data for factors identified as leading to crises in ministry. Data were collected from a random stratified sample of Uniting Church clergy based in southern Australia. Three phases (Phase 1 $N=85$, Phase $2 N=95$, Phase $3 N=75$ ) identified precipitants to crises in ministry and strategies to mitigate these crises. Strategies included a need for ongoing mandatory professional development, professional supervision, peer support, and formal ethics training. Results are

\footnotetext{
${ }^{1}$ B Fallon (Contact)

Professor of Psychology

School of Psychology, Deakin University
}

221 Burwood Highway

Burwood, Victoria 3125 Australia

E-mail: barryjfallon@gmail.com

Telephone: +613413401570

${ }^{2}$ Simon Rice

Psychologist

Orygen Youth Health

Melbourne, Australia

${ }^{3}$ Joan Wright Howie

Habitat Uniting Church

Melbourne, Australia 
discussed in the light of job demands, job control and job support, and the self-determination needs of competence, relatedness, and autonomy.

Keywords Vocational crisis, Burnout, Clergy, Health

\section{Introduction}

While clergy most commonly exercise their ministry in congregations, many also work as chaplains or administrators in a variety of settings such as schools, aged care, prisons, and church or community agencies. As such, clergy are involved in networks of working relationships with individuals, families, communities, and the institutional church hierarchy (Kaldor \& Bullpit, 2001). Embedded within each of these relationships are complex expectations about how the role will be fulfilled encompassing denominational, community, divine, and self expectations (Hambly, 1969). The clergy's own theological framework, training, styles of operating, and priorities determine the ways in which they fulfil their ministry. Inevitably, the expectations will not always be in accord, and conflict will arise. The demands created by these numerous relationships and expectations create an increasingly complex set of issues that have the potential for both significant reward and great frustration and difficulty (Hill, 2003).

Within Australia, most religious denominations are faced with decreasing attendance at worship services (Miner, Dowson, \& Sterland, 2010). Many local congregations are struggling financially, and most denominations are dealing with increasing numbers of clergy retiring or leaving the ordained ministry early (Webber, Singleton, Joyce, \& Dorissa, 2010). In conjunction with these changes, many clergy report a lack of personal space and a feeling of being always 'on call.' Clergy are often required to move to a different parish or employment context, which impedes the development and maintenance of lasting 
relationships (Hill, Darling, \& Raimondi, 2003). It is not surprising that these factors can induce burnout in clergy, a psychological condition that results from chronic stress (Maslach, Schaufeli, \& Leiter, 2001). Burnout is most commonly conceptualized across three domains; emotional exhaustion, where the person feels emotionally drained by his or her work; depersonalization, or a response of cynicism and withdrawal from people; and a low sense of personal accomplishment (Miner, 2007a).

Research suggests that one quarter of church leaders in Australia experience burnout as an extreme or significant issue (Miner, Dowson, \& Sterland, 2009). Further, data from a large-scale survey of clergy reported that $56 \%$ of church leaders could be described as borderline to burnout (Kaldor \& Bulpitt, 2001). Han and Lee (2004) investigated demands and stress among Korean American pastors, exploring the impact of boundary ambiguity (that is, lack of clear boundaries concerning the pastoral role) and expectations of pastors' flexibility and availability. Their findings support the proposition that these two phenomena were negatively associated with pastors' wellbeing and positively associated with symptomatic stress.

Some authors suggest that the crises experienced by many clergy are typical of those experienced in other professions. As individuals move through their career, the early and mid-career stages are especially critical (Pryor, 1981), with many ministers voluntarily resigning mid-career (Ragsdale, 1978). The pressures of ministry, however, are noticeable from the beginning, and those in the early years of ministry appear significantly more vulnerable to emotional exhaustion (Francis, Kaldor, Shevlin, \& Lewis, 2004). For example, graduates of theological college experience moderate levels of burnout due to conflict, expectations, and loss of parishioners (Miner, 2007a). Consistent with this, other studies highlight the prevalence of emotional exhaustion, depersonalization, and a lack of a sense of personal accomplishment among clergy (e.g., Doolittle, 2007; Miner, 2007b; Randall, 2007; 
Turton \& Francis, 2007). Increases in hours worked, congregation size, and clergy age have all been related to greater clergy burnout (Francis, Hills, \& Kaldor , 2009). Similarly, Fairlie, Smith, and Fagan (2006) reported that many clergy feel overworked and report inadequate time for self-reflection. Fairlie and colleagues also reported that clergy frequently feel powerless to influence change within the church structures and often have difficulty in identifying others whom they can trust and confide in. Of particular concern, this social isolation and role ambiguity contributed to depression, anxiety, and stress scores for the clergy that were higher than general community levels.

\section{The present study and its theoretical frameworks}

The research cited above suggests that many clergy experience some form of crisis in the course of their ministry and that existing institutional church structures have limited capacity to provide adequate prevention or support for ministers in crisis. It is within this context that the current study was commissioned by the Ministers in Crisis Task Group of the Uniting Church in Australia, Synod of Victoria and Tasmania, to identify the specific precipitants of crises faced by clergy. The Task Group set two broad research aims: first, to identify the broad range of factors which clergy believe lead to crises in ministry, and second, to identify what actions clergy consider should be taken by the institutional church to prevent or mitigate such crises in the future. In order to meet these research aims, the current study adopted a mixed-method design. As such, rather than relying on the formal development of testable hypotheses derived from theory and past research, the first phase of data collection proceeded from open-ended questions. Responses to these questions then served to inform the subsequent phases of the research process. In order to interpret the overall results of the study, two theoretical frameworks were adopted post hoc. The two theories utilized were self 
determination theory (SDT; Ryan \& Deci, 2000) and the Job Demand-Control-Support model (JDCS model; Johnson \& Hall, 1988).

SDT posits that there are three basic human motivations required to enable humans to thrive and grow: needs for competence, relatedness, and autonomy. According to SDT, people must feel that they are succeeding at optimally challenging tasks, that they have meaningful personal attachments to others, and that their behaviors are in some way selfdetermined. SDT assumes that social contexts which facilitate satisfaction of these three basic needs will support people's inherent nature to strive for wellbeing; conversely, social conditions which thwart need satisfaction will hinder innate growth-oriented propensities (Deci \& Ryan, 2000). For clergy, autonomy, sense of competency, and personal relatedness can all be threatened by the ambiguous nature of their work demands, church communities, and institutional structures.

The Job Demand-Control-Support (JDCS) model is one of the most widely used models in occupational research to measure work stress and strain outcomes (Hurrell, Nelson \& Simmons, 1998). Within the JDCS model, job demands include amount of work, concentration, due dates for work, task requirements, physical exertion, problem solving, and conflicting demands (Karasek \& Theorell, 1990). Job control refers to the individual's potential control over tasks and conduct within the job. The JDCS iso-strain hypothesis (isomeaning isolation) proposes that when demands are high, control is low, and social support is also low, then strain outcomes are most severe (Karasek \& Theorell). Several studies have found that work relationships can be sources of stress and both psychological and physiological strain outcomes (Theorell \& Karasek, 1996).

The job demands on clergy arise from the differing audiences or groups to whom the clergy are accountable (e.g., Han \& Lee, 2004; Hill, Darling, \& Raimondi, 2003). In terms of job control, clergy often report powerlessness in being able to effect changes in matters that 
impact them (Fairlie, Smith, \& Fagan, 2006), and clergy seldom have sufficient time to accomplish all their role demands (Hill, Darling, \& Raimondi, 2003). Within the SDT model, while the clergy may appear to be working in a relatively autonomous manner, the demands on their time and the multiple role expectations do not provide them with a sense of autonomy whereby they can feel effective in their work. When it comes to competency within this model, there are no agreed-upon clear markers for clergy success. Is effectiveness to be seen in terms of the financial status of the church, the number of parishioners attending worship, or the faithfulness of members?

Relatedness is the third construct within the SDT model, and clergy frequently report feelings of isolation (e.g., Fairlie, Smith, \& Fagan, 2006). Whilst fostering relationships is a primary function of clergy, their standing as ordained sets them apart from the communities with which they minister. Thus, the experience of relatedness is always through a particular role relationship, not simple mutuality. Further, in some denominations clergy move house and community every 5-10 years (Kaldor \& Bullpit, 2001), often diminishing any sense of relatedness, not only in the work context, but also in their local community.

\section{Method}

Methodological approach

Participants provided online data across three successive phases using an iterative methodology adapted from the Delphi technique (see Rowe \& Wright, 1999). The Delphi technique is a procedure that seeks to obtain a reliable consensus of opinion from a group of experts by a series of rigorous questionnaires interspersed with controlled opinion feedback (Dalkey \& Helmer, 1963). In the current study, a mixture of qualitative and quantitative methodologies were used. Phase 1 invited participants to identify and specify the important factors which lead to crises in ministry. Phase 2 invited participants to provide quantitative 
ratings of the importance of each of the factors identified in Phase 1. Phase 3 invited participants to provide qualitative suggestions as to what should be done to address the six most important factors identified in Phase 2.

\section{Participants}

The Uniting Church Synod of Victoria and Tasmania has a total population of 782 ministers, comprising 480 ministers in placement and 302 retired ministers. To ensure that the researchers were unaware of the identity of participants, a representative from the Task Group sent an email invitation to a stratified random sample representing $25.7 \%(N=201)$ of the total minister population within the region. The initial sample pool was stratified to include 51 female ministers and 20 retired ministers.

The number of participants responding varied across the three data collection phases (see Table 1). In each instance the response rate was more than adequate and was considerably larger than the average response rate expected in organizational research (e.g., Baruch \& Holtom, 2008). In response to the Phase 1 email, three male participants requested their name be withdrawn from the email list — these participants were subsequently not contacted for any further data collection. Two emails were returned from unrecognized email addresses and were therefore not included in the data.

\section{Insert Table 1 here}

At each of the three data collection phases, the stratified random sample was emailed and invited to participate. Because the respondents were assured anonymity, the overlap of participants across the three phases cannot be determined. Consequently, some participants may have participated in all three phases and some in only one or two. Data were not collected on the age of participants for concern that individuals might be identifiable. There was minor variation among the three phases in terms of the representation of males and 
females, types of placement, geographical regions, ethnicity, and years since ordination (see Table 2). Broadly speaking, however, the sample demographics approximated the demographics of ministers across the Synod.

[Insert Table 2 here]

\section{Procedure}

Ethics approval was received from the relevant Human Research Ethics Committee. At Phase 1, email invitations were sent out to all 201 potential participants. The email invitation contained a hyperlink to a secure website where participants could view the information letter and complete the survey. The information letter indicated that the project had been commissioned by the Synod Crisis in Ministry Task Group and sought to identify the most important factors which precipitated crises in ministry and ways in which such crises could be attended to and mitigated in the future. Rather than providing specific examples to participants, broad parameters were set, with the term 'crisis' defined as a state that may be related to less than effective functioning as a minister, or as experiencing a lack of confidence in the vocation or vocational identity.

Phase 1 adopted a qualitative approach in which participants were invited to provide up to five factors they considered important in leading to "crises in ministry." It was indicated that if participants could think of more than five factors, then they ought to choose the five most important. Participants were invited to think about both their own ministry and the ministry of other ministers they knew. Responses could be within the range of one to 200 words. The email invitation informed participants that the website would remain accessible for a two-week period. To encourage a high response rate, a combined thank you to those that had participated and a reminder to those who had not participated was sent to all in the sample one week prior to the website being closed. 
Following Phase 1, a further email was sent to the sample of participants inviting them to participate in Phase 2. The hyperlink embedded within the email directed participants to the secure website for Phase 2. Participants were presented with an alphabetical listing of all factor themes and theme descriptors identified in Phase 1. Participants were then invited to provide a quantitative rating for each factor for the level of importance they believed that factor held for creating crises in ministry. The rating scale used ranged from $1=$ not at all important to $7=$ extremely important. For example, the first factor and descriptor presented was Boundaries, e. g., lack of attention to and lack of awareness of professional and personal boundaries in ministry. This includes issues of confidentiality, gossiping, and acting beyond the role of a minister, e.g., trying to be all things to all people. The brief description for each factor was written to reflect the variations in the common sub-themes of the factor as mentioned by participants.

Subsequent to the data analyses of Phase 2, a further email was sent out to the sample of participants inviting them to contribute to the third and final phase. Phase 3 presented the six factors with the highest mean ratings of importance identified from Phase 2 . The six were chosen as they corresponded to those factors for which at least $50 \%$ of the sample gave a rating of 6 or 7 on the 7-point rating scale. Participants were invited to provide qualitative responses as to what should be done to address each of the six factors in mitigating their likelihood to precipitate a crisis in ministry. The six factors in order were: Boundaries; Conflict; Power, Abuse, Bullying; Personal Wellbeing; Faith; and Change. 


\section{Results}

Phase 1

Data were downloaded from the secure website and collated for analysis. The 85 participants in Phase 1 provided a total of 353 responses naming factors considered important in leading to crises in ministry. On average this equates to 4.2 responses per participant. Two researchers each examined the full set of responses and independently created categories based on common themes present within the data. The researchers then agreed on the list of categories. Subsequent to this, each researcher independently categorized the 353 responses. Finally, the researchers met again and discussed the categorization of each response until final agreement was reached.

The data reduction process resulted in 18 separate factors considered important in leading to crises in ministry. The factor descriptors, frequency of mention, and rank ordering (based on frequencies) of the 18 factors are presented in Table 3. Factor descriptors were constructed in such a way as to represent the common sub-themes within each factor.

[Insert Table 3 here]

The frequency of mention for each of the 18 factors varied considerably from 51 mentions for Expectations to 4 mentions for Training. From this it is clear that the participants who responded had no difficulty in identifying factors which they considered significant in leading to crises in ministry, but some factors were easier for participants to articulate and quantify than others.

\section{Phase 2}

Phase 2 invited participants to provide quantitative ratings reflecting the level of importance each of the 18 factors displayed in Table 3 has for precipitating a crisis in ministry. 
Participants were presented with the factor labels in alphabetical order along with the associated descriptors (see Table 3). They were asked to rate the importance of each factor on a seven-point scale (see Table 4). On average, all 18 factors were considered to have at least some level of importance, the lowest mean rating of 3.90 being only slightly lower than the mid-point of the seven-point scale. Eight factors had an average rating of greater than 5.00.

[Insert Table 4 here]

For all 18 categories, the importance ratings by females were higher than that of the males, and on four of these (Boundaries $p=.042$; Conflict $p=.029$; Power, Abuse, Bullying $p=.046$; and Theological Differences $p=.037$ ) the differences between males and females were statistically significant. The rank orderings of the importance for the males and the females were very similar. There were no significant differences in mean importance ratings between clergy in local congregations and clergy in other types of placements.

Particular attention was given to the factors assigned the highest importance ratings. It was decided for the next phase of the research to focus on those factors for which at least half of the sample gave a rating of 6 or more on the seven-point rating scale. Correlations between these six factors are displayed in Table 5. Correlations indicate moderate positive associations between Conflict and Power, Abuse, Bullying; Boundaries and Personal Wellbeing; and Personal Wellbeing and Faith. Faith is clearly an underlying factor as it was the only factor of the six to correlate significantly with every other factor.

[Insert Table 5 here]

Phase 3 
The final phase invited participants to provide action recommendations for the 6 factors that received the highest ratings of importance in Phase 2. Participants in Phase 3 varied in the number of recommendations made, from a low of 57 participants making recommendations for the Change factor to a high of 72 participants making recommendations for the Boundaries factor. Some participants made a single suggestion, while others made multiple suggestions. In a similar manner to Phase 1, the data provided by the participants were coded into categories through an iterative process by the researchers until agreement was met. Table 6 displays data in which recommendations for at least one factor were made by at least $10 \%$ of the sample.

\section{[Insert Table 6 here]}

The recommendations by the participants for the Conflict and the Power, Abuse, Bullying factors were very similar, with the most frequently mentioned suggestion being Mandatory Professional Development (33 mentions for Conflict and 21 mentions for Power, Abuse, Bullying). The next most frequently mentioned suggestion was for a Strengthening of the Complaints Procedures (15 mentions for Conflict and 17 mentions for Power, Abuse, Bullying). The next two suggestions were for Peer Support and Professional Supervision, although the order was different for each of the factors: the order was Peer Support (12 mentions) then Professional Supervision (10 mentions) for Conflict and the reverse order for Power, Abuse, Bullying (14 mentions for Professional Supervision and 10 mentions for Peer support). For Power, Abuse, Bullying an additional suggestion of providing workshops on these themes was mentioned (10 times).

Recommendations for Personal Wellbeing were for Professional Supervision (30 mentions), Peer Support (17 mentions), and Mandatory Professional Development (13 
mentions). Professional Supervision was also mentioned frequently for Conflict and for Power, Abuse, Bullying.

The Boundaries factor received the highest number of suggestions for what should be done (142) from the highest number of participants (72). For the Boundaries factor, Professional Supervision (25) was the most-mentioned process to address the matter. Following this was Mandatory Professional Development (21) and Mandatory Professional Development with a focus on Ethics (21). Peer Support (14) and Initial Training (9) were the other activities/processes that were suggested by more than a couple of participants. In effect, the participants who provided data on the Boundaries factor saw the ways in which it could be addressed somewhat differently from the other factors. This was the factor with the highest number of mentions for both Initial Training and for Mandatory Professional Development in Ethics (21).

The Change factor was a difficult one for the participants to make suggestions about. Mandatory Professional Development (23) and Peer Support (10) were the only two activities that were mentioned by at least 9 participants. It was on this factor that the highest number of participants provided data that the researchers could not readily code into appropriate categories. Reponses here included many "I don't know what to do about this" and examples of personal life situations which did not offer suggestions about what should happen. The Change factor was the only one which had a very low number of mentions for Professional Supervision (3).

The final factor considered was Faith. This factor had 9 participants who provided data that were not amenable to coding. Peer Support was the most frequently mentioned suggestion (21); Spiritual Direction and Retreats were mentioned by 17 participants each, and Professional Supervision by 15 . 
Overall, there was a reasonable degree of consistency in the recommendations across the factors. Mandatory Professional Development, Professional Supervision, and Peer Support were the most frequently mentioned activities suggested by the participants. The Strengthening of the Complaints Procedures was suggested especially with respect to the factors of Conflict and of Power, Abuse, Bullying. Retreats and Spiritual Direction are clearly indicated as processes which may address the crises of faith which clergy experience.

\section{Discussion}

Ask ministers of religion to tell you what they do, and the answers will be varied and wideranging. Tasks include baptising and burying, supporting people in their work and struggles, attending meetings, managing property, community development, preparing and conducting worship, praying, and teaching. Ask them why they decided to become a minister, and the answer will be the same - that they feel called by God through the church into a life of service. Yet, when Ministers are asked how they experience their job, many will tell stories of vocational crisis, burnout, bullying, anxiety, and depression. The present study sought to identify the precipitants and solutions to the commonly identified crises in ministry that ministers themselves perceive as being most important.

Clergy participating in the present study were able to identify a broad range of factors precipitating crises in ministry. The frequency of mentions did not necessarily imply importance. For example, the Expectations factor was the most frequently identified but was considered the seventh most important factor. This study provides new information about both the precipitants of crisis and the relative contribution each precipitant makes towards generating crisis. Of note, the mean importance ratings indicated that all but two of the 18 factors were beyond the midpoint of the seven-point scale. This demonstrates that the present 
sample considered almost all of the 18 factors to have a detrimental impact on clergy functioning.

Applying the framework of self-determination theory, of the factors identified as most important—Boundaries; Conflict; and Power, Abuse, Bullying — each corresponds to the interpersonal domain. The presence of these three factors in any large amount within a minister's work will likely erode a sense of positive connection and relatedness to others. Further, Conflict; Power, Abuse, Bullying, and issues related to Personal Wellbeing may also impair ministers' sense of competence and autonomy in their day-to-day role. In addition, issues related to contemporary society may exacerbate ministers' concerns related to the Faith and Change factors, which may further weaken any sense of competence and autonomy. It is theorized that social contexts that thwart relatedness, competence, and autonomy hinder human growth (Deci \& Ryan, 2000). Given the ambiguous and conflicting nature of demands on clergy (Hambly, 2003; Hill, 2003), coupled with situational difficulties that are likely to arise in the course of the diverse roles undertaken by clergy (Kaldor \& Bulpit, 2001), the factors identified as most important by the clergy may impede self-determination and exacerbate any vulnerability to crisis.

Within the framework of the Job Demand-Control-Support model, the factors identified as most important by the clergy can each be seen to have a negative impact on the demands experienced by clergy members in their work role. The iso-strain hypothesis within the JDCS model asserts that strain outcomes are most severe when demands are high and control and social support are low (Karasek \& Theorell, 1990). When combined with the ongoing isolation that many ministers experience (e.g., Fairlie, Smith, Fagan, 2006) and the lack of control that many ministers experience in their day-to-day work, from the JDCS perspective many clergy may be functioning under severe levels of strain. To address this, priority action items may include fostering greater supportive links between clergy to increase social support 
and providing clergy with greater opportunity for autonomy in their role (this may include mediation for dispute resolution in placements).

If operating in concert and left unchecked, factors identified as most important by the ministers may contribute to emotional exhaustion, depersonalization, and a low sense of personal accomplishment — the hallmarks of burnout (Maslach, Schaufeli, \& Leiter, 2001). Given that more than half of the present sample rated the highest six factors as very important, it is not surprising that high numbers of clergy report concerning levels of burnout and depression (Kaldor \& Bulpit, 2001; Miner, Dowson, \& Sterland, 2009). From the perspective of job demands, the six factors with the highest importance ratings can be viewed as exacerbating the demands of the clergy role.

Consistent with Francis, Hills, and Kaldor (2009), who reported that demographic factors and working conditions were poor predictors of clergy burnout, the current study failed to find demographic differences for the factors that lead to crisis. The exception to this was gender, in that females rated Boundaries; Conflict; Power, Abuse, Bullying; and Theological Differences higher than did males. Francis and colleagues argue that individual differences in personality and personal predispositions predict burnout susceptibility. Regardless of predisposing factors, the onus remains on the church agency to provide adequate support to mitigate crises amongst the clergy workforce. Ministers identified two forms of actions as applicable to each of the six factors: Mandatory Professional Development and Peer Support. They identified an additional form of action as applicable to 5 of the 6 factors (Change was the factor which was not included): Professional Supervision. These three forms of action are indicative of ministers feeling a need for closer collegial linkages amongst the clergy (Fairlie, Smith, \& Fagan, 2006). Participants in the current study also expect that the support provided should be offered in a professional manner by persons who have the appropriate training and expertise. It may not necessarily be by a person 
occupying a particular role, e.g., Presbytery Minister; the person's competence and expertise is more critical than their role.

It is important to note that there is a clear difference between Professional Supervision and Peer Support. Professional Supervision requires a relationship with another who has been trained as a Supervisor, and the process of Professional Supervision implies that there is a dimension of accountability from the supervisee to the supervisor. There is also typically a financial cost. Peer Support requires a relationship with one or more persons who are "the same.' Through their mutual understanding of the roles they share and their knowledge, they are able to support and assist each other. There is no necessary element of accountability in such a process.

Results also suggest that a significant number of participants viewed the current Uniting Church processes for handling complaints with respect to Conflict and to Power, Abuse, Bullying as ineffective. Both the SDT and the JDCS models draw upon interpersonal processes as influencing optimal human functioning. Based on this, church agencies should look to ensure that clergy perceive complaints procedures as just, adequate, transparent, and effective.

Faith is essential to any practicing minister. It is therefore of particular interest that of the most important factors identified by clergy, Faith was significantly correlated with each other factor. Theological issues underpinning faith impact ministers' experience of all the factors identified in the research. Exploring the shape of a minister's theology and spiritual foundations in relation to crisis is an area of interest for future research. The strength of the relationship between Personal Wellbeing and Faith is noteworthy $(r=.47)$, indicating a close relationship between these two factors where diminished wellbeing is associated with greater difficulties maintaining spiritual practices or with a loss of faith. Future research adopting a longitudinal design may elucidate this relationship. A relationship of similar magnitude $(r=$ 
.43) was also noted between Personal Wellbeing and Boundaries. Taken together, lack of attention to Personal Wellbeing may be an important precipitant leading clergy to crises in ministry.

While the present research provides a novel contribution to the literature on clergy health and wellbeing, results must be interpreted within the context of the study's limitations. Although a greater than average response rate was achieved (e.g., Baruch \& Holtom, 2008), a significant proportion of those invited to participate chose not to provide data to some particular questions. Further, while one of the strengths of the current study was the use of a stratified random sample, this in turn restricted the overall size of the sample. It is possible that those clergy who failed to respond to the invitation to participate may have an alternate perspective of the precipitants of crises not represented in the findings discussed above. In addressing these points, future researchers adopting similar online methodologies may have greater success in gaining representative samples when online invitations are sent out to all members of the organization, thus eliminating any problems related to restricting the sample.

Although the use of anonymous online data collection techniques has been found to reduce socially desirable responding (Booth-Kewley, Larson, \& Miyoshi, 2007), this method of data collection may not have suited many within the present cohort, which likely comprised a large number of older adults who may be unfamiliar with or lack confidence in using new technology (to prevent possible identification of participants, the present study failed to collect data on age). In addressing these factors, future researchers may wish to employ both online and paper-and-pencil methodologies, in addition to collecting data on age to enable analysis of findings according to age cohorts.

This study explored the negative aspects of clergy experience. It is important to note that the ratings provided by the present sample were not necessarily reflective of the participants' own personal experience and may have reflected factors that clergy in this study 
suppose would lead to crisis. A natural extension of this research would be to collect data on actual clergy experience and to explore the relationship between crisis experience and individual differences (e.g., Francis, Hills, \& Kaldor, 2009). A further extension of this research would be to explore resilience factors in clergy and to ask clergy what they believe are the factors that lead to satisfaction in ministry. It would also be of interest to explore the role of posttraumatic growth (Tedeschi \& Calhoun, 2004) after clergy experience crisis in their ministry.

\section{Conclusion}

Ministers of religion play an important role in the life of communities. However, in the context of societal change and growing expectations, their roles are becoming increasingly complicated. Church agencies need to become more aware of the wellbeing of their clergy workforce and of the factors that precipitate crises in their ministry. This study identifies a range of areas for future exploration. Broad suggestions are made for mitigating the factors identified as most important by the clergy. The strategies imply a greater need for professionalism, structural supports, and investment in the health of clergy. 


\section{Acknowledgments}

Funding for this project was provided by the Ministers in Crisis Task Group of the Uniting Church in Australia, Synod of Victoria and Tasmania. The Task Group received funding from the Centre for Theology and Ministry Research Committee and the Synod of Victoria and Tasmania Pastoral Assistance Committee.

\section{References}

Baruch, Y., \& Holtom, B. C. (2008). Survey response rate levels and trends in organizational research. Human Relations, 61(8), 1139-1160.

Booth-Kewley, S., Larson, G. E., \& Miyoshi, D. K. (2007). Social desirability effects of computerised and paper-and-pencil questionnaires. Computers in Human Behavior, $23,463-477$.

Dalkey, N. C., \& Helmer, O. (1963). An experimental application of the Delphi method to the use of experts. Management Science, 9, 458-467.

Deci, E. L., \& Ryan, R. M. (2000). The "what" and "why" of goal pursuits: Human needs and the self-determination of behavior. Psychological Inquiry, 11, 227-268.

Doolittle, B. R. (2007). Burnout and coping among parish-based clergy. Mental Health, Religion \& Culture, 10, 31-38.

Fairlie, P., Smith, G., \& Fagan, S. (2006). The Survey of Ministry Personnel: Study of Isolation in Ministry for the United Church of Canada. Warren Shepell Research Group.

Francis, L. J., Hills, P., \& Kaldor, P. (2009). The Oswald Clergy Burnout Scale: Reliability, factor structure and preliminary application among Australian clergy. Pastoral Psychology, 57, 243-252. 
Francis, L.J., Kaldor, P., Shevlin, M., \& Lewis, C. A. (2004). Assessing emotional exhaustion among Australian clergy: Internal reliability and construct validity of the scale of emotional exhaustion in ministry (SEEM). Review of Religious Experience, 45, 269277.

Hambly, G. C. (1969). Mental and spiritual tensions in the ministry. Anvil-A Baptist Quarterly, 2, 6-7.

Han, J., \& Lee, C. (2004). Ministry demands and stress among Korean American pastors: A brief report. Pastoral Psychology, 53, 473-478.

Hill, E. W., Darling, C. A., \& Raimondi, N. M. (2003). Understanding boundary related stress in clergy families. Marriage and Family Review, 35, 147-166.

Hurrell, J., Nelson, D. L., \& Simmons, B. L. (1998). Measuring job stressors and strains: Where we have been, where we are, and where we need to go. Journal of Occupational Health Psychology, 3, 368-389.

Johnson, J. V., \& Hall, E. M. (1988). Job strain, work place social support, and cardiovascular disease: a cross-sectional study of a random sample of the Swedish working population. American Journal of Public Health, 78, 1336 -1342.

Kaldor, P., \& Bulpitt, R. (2001). Burnout in church leaders. Adelaide, Australia: Openbook. Karasek, R. (1979). Job demands, job decision latitude, and mental strain: Implications for job redesign. Administrative Science Quarterly, 24, 285-308.

Karasek, R., \& Theorell, T. (1990). Healthy work: Stress, productivity, and the reconstruction of working life. New York: Basic Books.

Lewis, C. A., Tutron, D. W., \& Francis, L. J. (2007). Clergy work-related psychological health, stress and burnout: An introduction to this special issue of Mental Health, Religion, and Culture. Mental Health, Religion, and Culture Culture, 10, 1-8. 
Maslach, C., \& Jackson, S. E. (1986). Maslach Burnout Inventory ( $2^{\text {nd }}$ ed.). Palo Alto, CA: Consulting Psychologists Press.

Maslach, C., Schaufeli, W. B., \& Leiter, M. P. ( 2001). Job burnout. Annual Review of Psychology, 52, 397-422.

Miner, M.H. (2007a). Changes in burnout over the first twelve months in ministry: Links with stress and orientation to ministry. Mental Health, Religion and Culture, 10, 916.

Miner, M.H. (2007b). Burnout in the first year of ministry: Personality and belief style as important predictors. Mental Health, Religion, and Culture, 10, 17-29.

Miner, M., Dowson, M., \& Sterland, S. (2009) Burnout and work satisfaction in Australian church leaders. InPsych, 31, 16-17.

Miner, M. H., Dowson, M., \& Sterland, S. (2010). Ministry orientation and ministry outcomes: Evaluation of a new multidimensional model of clergy burnout and job satisfaction. Journal of Occupational and Organizational Psychology, 83, 167-188.

Pryor, R. J. (1981). High calling high stress. Bedford Park, South Australia. Association for the Study of Religions.

Ragsdale, R.W. (1978). The mid-life crises of a minister. Waco, TX: Word Books.

Randall, K. J. (2007). Examining the relationship between burnout and age among Anglican clergy in England and Wales. Mental Health, Religion \& Culture, 10, 39-46.

Rowe, G., \& Wright, G. (1999): The Delphi technique as a forecasting tool: Issues and analysis. International Journal of Forecasting, 15, 353-375.

Ryan, R. M., \& Deci, E. L. (2000). Self-determination theory and the facilitation of intrinsic motivation, social development, and well-being. American Psychologist, 55, 68-78.

Tedeschi, R. G., \& Calhoun, L. G. (2004). Posttraumtic growth: Conceptual foundations and empirical evidence. Psychological Inquiry, 15, 1-18. 
Theorell, T., \& Karasek, R. A. (1996). Current issues relating to psychosocial job strain and cardiovascular disease research. Journal of Occupational Health Psychology, 1, 9-26.

Turton, D. W., \& Francis, L. J. (2007). The relationship between attitude toward prayer and professional burnout among Anglican parochial clergy in England: Are praying clergy healthier? Mental Health, Religion \& Culture, 10, 61-74.

Webber, R., Singleton, A., Joyce, M. R., \& Dorissa, A. (2010). Models of Youth Ministry in Action: The Dynamics of Christian Youth Ministry in an Australian City. Religious Education, 105, 104-215. 
Table 1. Participant Numbers and Response Rates for Each of the Three Phases

\begin{tabular}{cccccc}
\hline Phase & $\begin{array}{c}\text { Email } \\
\text { Invitations }\end{array}$ & $\begin{array}{c}\text { Total } \\
\text { Website Contacts }\end{array}$ & $\begin{array}{c}\text { Total } \\
\text { Responses }\end{array}$ & $\begin{array}{c}\text { Usable } \\
\text { Responses }\end{array}$ & Response Rate \\
\hline 1 & 201 & 133 & 133 & 85 & $42.5 \%$ \\
2 & 196 & 111 & 96 & 95 & $47.5 \%$ \\
3 & 196 & 116 & 77 & 75 & $38.5 \%$ \\
\hline
\end{tabular}


Table 2. Sample Descriptors for Gender, Ethnicity, Geographic Region, and Ministry

Type

\begin{tabular}{|c|c|c|c|}
\hline Demographic & Phase $1(\%)$ & Phase $2(\%)$ & Phase $3(\%)$ \\
\hline \multicolumn{4}{|l|}{ Ethnicity } \\
\hline Anglo & 91.7 & 88.0 & 92.1 \\
\hline Other than Anglo & 8.3 & 12.0 & 7.9 \\
\hline \multicolumn{4}{|l|}{ Gender } \\
\hline Male & 63.1 & 66.7 & 62.3 \\
\hline Female & 36.9 & 33.3 & 37.7 \\
\hline \multicolumn{4}{|l|}{ Geographical Region* } \\
\hline Metropolitan & 60.7 & 59.8 & 59.2 \\
\hline Regional City & 21.4 & 27.2 & 31.6 \\
\hline Rural & 25.0 & 23.9 & 23.7 \\
\hline \multicolumn{4}{|l|}{ Ministry Placement } \\
\hline Local Congregation & 67.9 & 68.8 & 67.1 \\
\hline Outreach & 7.0 & 4.3 & 3.9 \\
\hline Presbytery & 5.9 & 8.6 & 5.2 \\
\hline Chaplaincy & 4.8 & 3.2 & 5.2 \\
\hline Retired & 2.4 & 3.2 & 1.3 \\
\hline Synod & 2.4 & 2.2 & 2.6 \\
\hline Parachurch & 1.2 & 1.1 & 0.0 \\
\hline Patrol & 1.2 & 2.2 & 1.3 \\
\hline Research & 1.2 & 0.0 & 0.0 \\
\hline With an agency & 1.2 & 4.3 & 2.6 \\
\hline Education & 0.0 & 0.0 & 3.9 \\
\hline Not specified & 4.8 & 2.1 & 6.1 \\
\hline \multicolumn{4}{|l|}{ Years Since Ordination } \\
\hline Male & $22.1 \mathrm{yrs}$ & $21.3 \mathrm{yrs}$ & $22.8 \mathrm{yrs}$ \\
\hline Female & $15.1 \mathrm{yrs}$ & $16.1 \mathrm{yrs}$ & $15.0 \mathrm{yrs}$ \\
\hline
\end{tabular}

Note. * Geographical region totals more than $100 \%$ as some participants indicated their ministry occurred in more than one geographical region. 
Table 3. Identified Factors that Contribute to Crises in Ministry

\begin{tabular}{|c|c|c|c|}
\hline Rank & Factor & Descriptor & Freq \\
\hline 1 & Expectations & $\begin{array}{l}\text { Expectations of the role of minister, e.g., insufficient time to complete tasks, } \\
\text { clashing of expectations from different sources including self and } \\
\text { congregation, synod, presbytery, local community. Lack of clarity of } \\
\text { expectations of the minister's role, lack of challenge in ministry placement } \\
\text { and not meeting one's own goals. }\end{array}$ & 51 \\
\hline 2 & $\begin{array}{l}\text { Power, Abuse, } \\
\text { Bullying }\end{array}$ & $\begin{array}{l}\text { Misconduct, accusations of sexual impropriety, abuse and bullying by church } \\
\text { members or clergy. Experiencing interpersonal difficulties with gatekeepers, } \\
\text { congregation members, presbytery, or colleagues who wield power. }\end{array}$ & 41 \\
\hline 3 & Change & $\begin{array}{l}\text { Changes in aspects of ministers' experience due to contemporary society, e.g., } \\
\text { declining congregations and growing irrelevance of the church and parish } \\
\text { ministry to contemporary society, changes in belief, faith, and spirituality. }\end{array}$ & 36 \\
\hline 4 & $\begin{array}{l}\text { Personal } \\
\text { Wellbeing }\end{array}$ & $\begin{array}{l}\text { Lack of self-care including lack of self-awareness, lack of confidence, mental } \\
\text { health issues amongst the clergy and laity. Managing stress, overwork, } \\
\text { burnout, and exposure to trauma and others' burdens. Experiencing a personal } \\
\text { crisis. }\end{array}$ & 32 \\
\hline 5 & $\begin{array}{l}\text { Support, } \\
\text { Mentoring, } \\
\text { Supervision }\end{array}$ & $\begin{array}{l}\text { Lack of caring support from others, including the leadership within UCA, lack } \\
\text { of structured mentoring including spiritual mentoring and mentoring in initial } \\
\text { placements, lack of appropriate supervision. }\end{array}$ & 29 \\
\hline 6 & Faith & $\begin{array}{l}\text { Faith issues, e.g., spiritual burnout such as a breakdown in spiritual discipline, } \\
\text { spiritual neglect, or poor development of spiritual practices, a personal crisis } \\
\text { of faith, a loss or lack of faith. }\end{array}$ & 26 \\
\hline 7 & Isolation & $\begin{array}{l}\text { Social isolation from family and friends or professional isolation and feeling } \\
\text { disconnected from colleagues. }\end{array}$ & 22 \\
\hline 8 & Family & $\begin{array}{l}\text { Relationship issues within the family, difficulties at home, distance from } \\
\text { extended family, issues with spouse's work requirements, relationship } \\
\text { changes. }\end{array}$ & 22 \\
\hline 9 & Conflict & $\begin{array}{l}\text { Experiences of conflict, e.g., conflict between clergy and congregation } \\
\text { members, conflict within the congregation, conflict amongst clergy. }\end{array}$ & 22 \\
\hline 10 & Placement & $\begin{array}{l}\text { Inappropriate placement or mismatch of placement to minister. Disruptive } \\
\text { nature of placement process for self, family, and relationships. Condition and } \\
\text { location of manses. }\end{array}$ & 15 \\
\hline 11 & $\begin{array}{l}\text { Policy, } \\
\text { Protocol }\end{array}$ & $\begin{array}{l}\text { The institutional nature of church in which there is inadequate or ineffective } \\
\text { structures, processes, decision making, and governance. Lack of confidence in } \\
\text { church leadership. }\end{array}$ & 9 \\
\hline 12 & Discrimination & $\begin{array}{l}\text { Discrimination based on race, gender, sexuality, in-group/out-group, or type } \\
\text { of ministerial placements, e.g., specialized ministries such as school } \\
\text { chaplaincy. }\end{array}$ & 9 \\
\hline 13 & Boundaries & $\begin{array}{l}\text { Lack of attention to and lack of awareness of professional and personal } \\
\text { boundaries in ministry. This includes issues of confidentiality, gossiping, and } \\
\text { acting beyond the role of a minister, e.g., trying to be all things to all people. }\end{array}$ & 9 \\
\hline 14 & $\begin{array}{l}\text { Theological } \\
\text { Differences }\end{array}$ & $\begin{array}{l}\text { Theological and faith development differences between clergy and } \\
\text { congregation and also within congregation. }\end{array}$ & 8 \\
\hline 15 & Financial & $\begin{array}{l}\text { Poor remuneration, lack of tangible rewards, or lack of sufficient funds for the } \\
\text { church. }\end{array}$ & 7 \\
\hline 16 & Vocation & $\begin{array}{l}\text { Lack of clarity in vocation, clash between vocation and the way the church } \\
\text { operates, a crisis of vocation. }\end{array}$ & 6 \\
\hline 17 & Health & $\begin{array}{l}\text { Personal health matters that impact ability to function effectively as a } \\
\text { minister. }\end{array}$ & 5 \\
\hline 18 & Training & $\begin{array}{l}\text { Inadequate skills, e.g., listening skills, crisis management, conflict } \\
\text { management. }\end{array}$ & 4 \\
\hline
\end{tabular}


Table 4. Means and Standard Deviations for Factor Importance

\begin{tabular}{lcc}
\hline Factor & Mean & $S D$ \\
\hline Boundaries & 5.78 & 1.23 \\
Conflict & 5.66 & 1.23 \\
Power Abuse, Bullying & 5.61 & 1.29 \\
Personal Wellbeing & 5.45 & 1.34 \\
Faith & 5.34 & 1.41 \\
Change & 5.18 & 1.40 \\
Expectations & 5.15 & 1.35 \\
Family & 5.13 & 1.37 \\
Support, Mentoring, Supervision & 4.96 & 1.58 \\
Placement & 4.87 & 1.32 \\
Health & 4.85 & 1.45 \\
Isolation & 4.84 & 1.44 \\
Lack of Training & 4.56 & 1.42 \\
Discrimination & 4.51 & 1.56 \\
Vocation & 4.46 & 1.39 \\
Policy/Protocol & 4.32 & 1.50 \\
Theological Differences & 3.96 & 1.26 \\
Financial & 3.90 & 1.52 \\
\hline Note. Average importance values were within the range $1-7$. &
\end{tabular}


Table 5. Correlations between the Six Factors with the Highest Importance Ratings

\begin{tabular}{lllllll}
\hline & 1. & 2. & 3. & 4. & 5. & 6. \\
\hline 1. Boundaries & - & $.35^{* *}$ & .14 & $.43^{* *}$ & $.28^{* *}$ & $.24^{*}$ \\
2. Conflict & & - & $.54^{* *}$ & $.30^{* *}$ & $.29^{* *}$ & .17 \\
3. Power, Abuse, Bullying & & & - & .18 & $.27^{* *}$ & -.09 \\
4. Personal Wellbeing & & & & - & $.47^{* *}$ & .04 \\
5. Faith & & & & - & \multicolumn{2}{c}{$.29^{* *}$} \\
6. Change & & & & & - \\
\hline Note. $* p<.05$ (two tailed).** $p<.01$ (two tailed) & & & & &
\end{tabular}


Table 6. Frequencies of Recommendations for Action for Each of the 6 Factors

\begin{tabular}{lrrrrrrr}
\hline Recommended Action & Conflict & PWB & Bound & PAB & Change & Faith & Total \\
\hline Initial Training & 4 & 4 & 9 & 4 & 3 & 4 & 28 \\
Mandatory Professional Development & 33 & 13 & 21 & 21 & 23 & 15 & 126 \\
Ethics Training & 2 & 0 & 21 & 6 & 0 & 0 & 29 \\
Professional Supervision & 10 & 30 & 25 & 14 & 3 & 15 & 97 \\
Peer Support & 12 & 17 & 14 & 10 & 10 & 21 & 84 \\
Retreats & 1 & 7 & 2 & 0 & 2 & 17 & 29 \\
Spiritual Direction & 0 & 5 & 1 & 0 & 1 & 17 & 24 \\
Workshops & 4 & 0 & 4 & 10 & 1 & 0 & 19 \\
Strengthen Complaints Procedure & 15 & 0 & 1 & 17 & 2 & 0 & 35 \\
Participants (n=) & 66 & 61 & 72 & 58 & 57 & 62 & - \\
\hline
\end{tabular}

Note. $\mathrm{PWB}=$ Personal Wellbeing; Bound = Boundaries; $\mathrm{PAB}=$ Power, Abuse, Bullying. 